\title{
The microbiota regulates susceptibility to Fas-mediated acute hepatic injury
}

\author{
Stela Celaj ${ }^{1}$, Michael W Gleeson ${ }^{2}$, Jie Deng ${ }^{1}$, George A O'Toole ${ }^{1}$, Thomas H Hampton ${ }^{1}$, Martin F Toft ${ }^{3}$, \\ Hilary G Morrison ${ }^{4}$, Mitchell L Sogin ${ }^{4}$, Juan Putra ${ }^{5}$, Arief A Suriawinata ${ }^{5}$ and James D Gorham ${ }^{1,5}$
}

Whereas a significant role for intestinal microbiota in affecting the pathogenesis and progression of chronic hepatic diseases is well documented, the contribution of the intestinal flora to acute liver injury has not been extensively addressed. Elucidating the influence of the intestinal microbiota on acute liver inflammation would be important for better understanding the transition from acute injury to chronic liver disease. Using the Concanavalin A (ConA)-induced liver injury model in laboratory mice, we show that the severity of acute hepatic damage varies greatly among genetically identical mice raised in different environments and harboring distinct microbiota. Through reconstitution of germ-free (GF) mice, and the co-housing of conventional mice, we provide direct evidence that manipulation of the intestinal flora alters susceptibility to ConA-induced liver injury. Through deep sequencing of the fecal microbiome, we observe that the relative abundance of Ruminococcaceae, a Gram(+) family within the class Clostridia, but distinct from segmented filamentous bacteria, is positively associated with the degree of liver damage. Searching for the underlying mechanism(s) that regulate susceptibility to ConA, we provide evidence that the extent of liver injury following triggering of the death receptor Fas varies greatly as a function of the microbiota. We demonstrate that the extent of Fas-induced liver injury increases in GF mice after microbiota reconstitution, and decreases in conventionally raised mice following reduction in intestinal bacterial load, by antibiotic treatment. We also show that the regulation of sensitivity to Fas-induced liver injury is dependent upon the toll-like receptor signaling molecule MyD88. In conclusion, the status and composition of the intestinal microbiota determine the susceptibility to ConA-induced acute liver injury. The microbiota acts as a rheostat, actively modulating the extent of liver damage in response to Fas triggering.

Laboratory Investigation (2014) 94, 938-949; doi:10.1038/labinvest.2014.93; published online 28 July 2014

Some 10 trillion bacteria, with a total weight of up to $2 \mathrm{~kg}$, reside in the human intestine. ${ }^{1}$ Bacterially derived constituents, such as lipopolysaccharide (LPS), enter the liver through the portal circulation, resulting in continuous exposure of the liver to high concentrations of a wide array of intestinederived bacterial products. The intestinal microbiota influences the progression of a large variety of chronic liver diseases including non-alcoholic fatty liver disease, primary biliary cirrhosis, and alcoholic liver disease. ${ }^{2,3}$ By contrast, far less is known about the influence of the microbiota on acute liver injury. Establishing whether the microbiota can modulate acute liver injury would be important, since chronic liver disease is typically preceded by, and results from, episodes of acute injury that recur or never relent. Understanding the factors that impact the extent of acute liver injury is necessary to understand how acute injury may transition to chronic liver disease, with its attendant sequelae of fibrosis, cirrhosis, and the requirement for orthotopic liver transplant.

Toll-like receptor (TLR) pathways are important for mediating the influence of the microbiota on the severity and extent of pathology due to chronic liver disease. ${ }^{4,5}$ Recent reports using mouse models provide clear evidence that activation of TLR pathways can also modulate the extent of damage in acute liver injury. For example, liver damage

\footnotetext{
'Department of Microbiology and Immunology, The Geisel School of Medicine at Dartmouth, Lebanon, NH, USA; ${ }^{2}$ Department of Medicine, The Geisel School of Medicine at Dartmouth, Lebanon, NH, USA; ${ }^{3}$ Taconic Farms Inc., One Hudson City Center, Hudson, NY, USA; ${ }^{4}$ Josephine Bay Paul Center for Comparative Molecular Biology and Evolution, Marine Biological Laboratory, Woods Hole, MA, USA and ${ }^{5}$ Department of Pathology, The Geisel School of Medicine at Dartmouth, Lebanon, NH, USA

Correspondence: Dr JD Gorham, MD, PhD, Department of Pathology, The Geisel School of Medicine at Dartmouth, HB7600, One Medical Center Drive, DHMC, Lebanon, $\mathrm{NH}$ 03756, USA.

E-mail: james.d.gorham@dartmouth.edu

Received 1 April 2014; revised 11 June 2014; accepted 17 June 2014
} 
resulting from administration of the hepatotropic $\mathrm{T}$ cellactivating lectin Concanavalin A (ConA) is reduced in mice deficient for the TLR signaling molecule MyD88, ${ }^{6}$ suggesting that bacterial-derived substances augment ConA-mediated damage. Consistent with this observation, ConA-induced inflammation and injury is ameliorated in mice treated with antibiotics, or deficient in TLR4, ${ }^{7}$ implicating TLR4 ligands (eg, LPS) in modulating disease. Similarly, TLR4 on bone marrow-derived cells is critical for the development of acute liver injury following warm ischemia/reperfusion. ${ }^{8} \mathrm{CpG}$ can enhance ConA-mediated liver damage through a TLR9dependent pathway. ${ }^{9}$ TLR9 also exacerbates acute liver damage due to acetaminophen toxicity. ${ }^{10}$

Given the influence of the microbiota on chronic liver diseases, the demonstrated roles for TLR signaling in mediating the effects of microbiota on chronic liver disease, and reports demonstrating that TLR signaling pathways influence acute liver injury, we hypothesize that acute immune-mediated liver injury can be modulated by the intestinal microbiota. We tested this hypothesis using the murine model of ConA-induced acute liver injury. ConA administration rapidly induces activation of hepatic invariant natural killer $\mathrm{T}$ (iNKT) cells and conventional CD4 T cells, ${ }^{11}$ which, in concert with macrophages ${ }^{12}$ and neutrophils, ${ }^{13}$ cause acute liver damage through a pathway that involves release of a panoply of cytokines and requires the participation of the Fas death receptor pathway. ${ }^{14}$

Here, we directly demonstrate that the microbiota modulates acute liver injury induced by ConA. In addition, we provide experimental evidence that the Fas response pathway is an important target of regulation by the microbiota.

\section{MATERIALS AND METHODS}

\section{Animal Breeding and Cohousing}

Female BALB/cJ mice obtained from the Jackson Laboratory (JAX) were established as a breeder colony at the Geisel (GSL) School of Medicine for $>4$ generations according to Association for Assessment and Accreditation of Laboratory Animal Care guidelines, allowing them to habituate to GSL environmental conditions. In some experiments, 3-week-old female $\mathrm{BALB} / \mathrm{cJ}$ mice purchased from JAX were co-housed with 3-week-old GSL-habituated BALB/cJ mice: per cage, two JAX BALB/cJ mice were co-housed with two GSL-habituated $\mathrm{BALB} / \mathrm{cJ}$ mice for an additional 5 weeks, and then challenged with ConA. To assess the influence of vendor environment, age-matched $\mathrm{BALB} / \mathrm{c}$ and $\mathrm{C} 57 \mathrm{Bl} / 6$ mice were purchased from JAX, Taconic Farms (TAC), and National Cancer Institute (NCI), and housed at GSL for $<1$ week (to minimize shifts in microbiota composition) before challenge. For Myd88 KO and Fas KO experiments, B6.129P2(SJL)-Myd88 ${ }^{\text {tm } 1 \text { Defr }} / \mathrm{J}$ mice and B6.MRL-Fas ${ }^{l p r} / \mathrm{J}$ mice were purchased from JAX, and either used within 1 week, or bred at GSL with JAX C57BL/6J mice, to allow for the generation of all genotypes as littermates that would be exposed to similar microbiota. Heterozygote offspring were set up as brother-sister breeders, and offspring genotyped (wild-type, heterozygote, or homozygote), and challenged to induce liver damage, as described below.

\section{Liver Injury Models}

In all, 6- to 8-week-old mice were challenged IV with $15 \mu \mathrm{g} / \mathrm{g}$ ConA (Sigma-Aldrich) diluted in sterile saline. Blood was collected retro-orbitally just before, and $6 \mathrm{~h}$ after ConA administration. Mice were killed at $24 \mathrm{~h}$ post challenge for collection of blood and liver tissue. For Fas-induced liver injury, mice received an IP injection of the agonistic anti-Fas mAb Jo-2 (BD Pharmingen) at $0.05,0.1$, or $0.2 \mu \mathrm{g} / \mathrm{g}$ as indicated; at various time points, liver and blood were collected. For carbon tetrachloride $\left(\mathrm{CCl}_{4}\right)$ liver injury, mice received a single IP injection $(2 \mu \mathrm{l} / \mathrm{g}$ in corn oil), and blood and tissue were collected at $24 \mathrm{~h}$. Alanine aminotransferase (ALT), aspartate aminotransferase (AST), and lactate dehydrogenase (LDH) activities were measured in plasma as described. ${ }^{15}$ For every mouse, the pre-injection plasma ALT level was measured, and was consistently in the range of 20-80 U/l; these baseline data are not depicted.

\section{Antibiotic Treatment and Microbiota Reconstitution}

$\mathrm{JAX} \mathrm{BALB} / \mathrm{c}$ mice were treated for 2 weeks with $1.0 \mathrm{~g} / \mathrm{l}$ ampicillin, $1.0 \mathrm{~g} / \mathrm{l}$ neomycin, $1.0 \mathrm{~g} / \mathrm{l}$ metronidazole, and $0.5 \mathrm{~g} / \mathrm{l}$ vancomycin administered with Splenda in the drinking water. Control mice received Splenda water. Fecal matter was collected before and after treatment. Bacterial DNA was isolated and quantitated as below. For reconstitution of microbiota, fecal pellets from 5 -week-old JAX BALB/c donor mice were homogenized in phosphate-buffered saline (PBS). In all, $100 \mu \mathrm{l}$ slurries were gavaged into 5-week-old GF SwissWebster mice from TAC.

\section{Flow Cytometry}

Following liver perfusion via the portal vein, tissue was dissociated in PBS with $10 \%$ fetal calf serum. Following a low speed spin to pellet hepatocytes, the supernatant was subject to a $40 \%$ Percoll gradient to isolate liver mononuclear cells (MNC). MNC were passed twice through $70 \mu \mathrm{m}$ filters. Single-cell suspensions in PBS were incubated with viability dye, Fc-blocked (anti-CD16/CD32; eBioscience), and stained with mAbs to $\mathrm{CD} 45, \mathrm{CD} 4, \mathrm{CD} 8 \alpha, \mathrm{TCR} \beta, \mathrm{CD} 11 \mathrm{~b}, \mathrm{CD} 49 \mathrm{~b}$ (clone DX5), GR-1, CD11c, and CD19 (Biolegend). iNKT cells were identified using PBS-57 tetramer, with empty CD1d tetramer as a control (NIH tetramer facility). Cells were washed and fixed in $1 \%$ paraformaldehyde and acquired on a MACSQuant (Miltenyi). Data analysis used FlowJo.

\section{Cytokine Quantification}

Livers were homogenized in $0.25 \mathrm{M}$ Sucrose, $10 \mathrm{mM}$ Tris, $\mathrm{pH}$ 7.4, Roche Protease Inhibitors at $120 \mathrm{mg}$ (wet weight) per milliliter. Lysates were spun (10000 RCF), and supernatants collected and stored at $-80{ }^{\circ} \mathrm{C}$. Millipore mouse 32-plex cytokine bead array, or enzyme-linked immunosorbent assay 
(for IL-22; Biolegend), was used for cytokine measurement as per manufacturer's protocol.

\section{Analysis of Genetic Background}

Mouse genetic backgrounds were assessed at the DartMouse ${ }^{\mathrm{TM}}$ Speed Congenic Core Facility at GSL. DartMouse uses the GoldenGate Genotyping Assay (Illumina, San Diego, CA) to interrogate 1449 single-nucleotide polymorphisms (SNPs) distributed throughout the genome. Raw SNP data were analyzed using the DartMouse's SNaP-Map ${ }^{\mathrm{TM}}$ and MapSynth $^{\mathrm{TM}}$ software.

\section{Fecal DNA Extraction and 16S Quantification}

As described, ${ }^{16}$ fecal samples were freshly collected and frozen at $-80{ }^{\circ} \mathrm{C}$ until processing. DNA extraction used the QIAamp DNA Stool Mini Kit (Qiagen). 16S gene copy quantification used $10 \mathrm{ng}$ fecal DNA and universal bacteria primers. PCRs were as described. ${ }^{17}$ SFB was quantified by specific QPCR as described. ${ }^{18}$

\section{S rRNA Deep Sequencing}

Deep sequencing, bioinformatic quality filtering, and operational taxonomic unit assignments were performed as described. ${ }^{19}$ Statistical analyses, abundance, Simpson diversity, and principal coordinates were calculated as described. ${ }^{20}$ The microbiome data sets have been deposited in the SRA database (SRP039453).

\section{Histology and Histopathological Scoring}

Livers were dissected and fixed in formalin at the time of euthanasia. Paraffin embedding, sectioning, and staining with hemotoxylin and eosin (H\&E) were per routine. An arbitrary scoring system was used to evaluate severity of liver damage as follows: (1) normal liver, no inflammation, or hepatocyte necrosis; (2) spotty necrosis/apoptosis or rare confluent necrosis; (3) confluent necrosis/apoptosis; and (4) large area of confluent necrosis with/without bridging necrosis. Scoring of livers was done in a blinded manner, such that the scorer was unaware of the treatment or group identity of any sample.

\section{Statistical Analyses}

Error bars represent standard deviation (s.d.). Statistical significance between two groups was determined using the Mann-Whitney $U$ test, as appropriate. Differences among $>2$ mouse groups were evaluated using the Kruskal-Wallis one-way analysis of variance. For cytokine profile comparisons, the statistical test used was the two-way repeated measures ANOVA, followed by a post hoc Tukey test. Significance is defined as $P<0.05$.

\section{RESULTS}

Mice from Different Vendors Exhibit Different Susceptibility to ConA-induced Liver Injury

We began with the broad hypothesis that environment has a critical effect on susceptibility to acute $\mathrm{T}$ cell-mediated liver injury. We administered ConA to groups of $\mathrm{BALB} / \mathrm{c}$ mice born and raised in distinct environments: Taconic Farms (TAC), National Cancer Institute (NCI), and the Jackson Laboratory (JAX). Although all groups exhibited liver injury, there was a clear vendor-specific effect. Specifically, JAX mice were more susceptible, exhibiting an $\sim 10$-fold-greater increase in plasma ALT and AST levels (Figure 1a and b). In addition, JAX BALB/c mice showed significantly more liver damage than did TAC BALB/c mice, as measured both by LDH (Figure 1c) and by histopathological scoring (Figure 1d). A similar vendor effect was observed for C57Bl/6 mice (Supplementary Figure 1). For subsequent experiments, we primarily compared JAX BALB/c mice with TAC BALB/c mice.

Genetic drift after decades of separate breeding may account for the phenotypic differences; however, genetic polymorphism analysis using a dense SNP panel showed minimal differences between JAX $\mathrm{BALB} / \mathrm{c}$ mice and TAC $\mathrm{BALB} / \mathrm{c}$ mice (Supplementary Figure 2). To definitively rule out genetics, we ConA-challenged genetically identical BALB/ cJ mice raised in different environments. BALB/cJ mice were imported from JAX and bred at Geisel (GSL) for several generations, to allow them to habituate to the new environment. ConA caused markedly less liver injury in GSL-bred $\mathrm{BALB} / \mathrm{cJ}$ mice than in freshly imported JAX $\mathrm{BALB} / \mathrm{cJ}$ mice (Figure 2a).

\section{Susceptibility to ConA-Induced Liver Injury is Transmissible between Co-Housed Mice and Modulated by Commensal Intestinal Flora}

Environmental factors to be considered include not only the microbiota, but also food, bedding, handling, etc. Among these, microbiota's effects should be transmissible between co-housed mice, whereas effects due to the other factors should not. Therefore, we co-housed JAX mice with GSLhabituated mice for several weeks, then challenged the mice with ConA. Control JAX mice and GSL mice responded with high and low susceptibility, respectively, as before. Co-housed mice exhibited intermediate susceptibility (Figure 2b; Supplementary Figure 3A). Importantly, co-housed GSL mice experienced the identical environment as did control GSL mice except for exposure to JAX mice, yet became more susceptible. Reconstitution of GF Swiss-Webster mice with fecal microbiota also enhanced susceptibility to ConA (Figure 2c; Supplementary Figure 3B). Together, these data demonstrate that environment modifies susceptibility to ConA-mediated liver injury in adult mice, and that such susceptibility is altered through manipulation of intestinal flora, as evidenced by the co-housing and GF-mouse reconstitution results.

\section{Composition of the Microbiota in JAX Mice and in TAC Mice}

The above results suggest that JAX $B A L B / c$ mice and TAC $\mathrm{BALB} / \mathrm{c}$ mice harbor distinct intestinal microbiota profiles, similar to results previously shown for $\mathrm{C} 57 \mathrm{Bl} / 6$ mice from these vendors. ${ }^{17}$ To test this hypothesis directly, we evaluated 

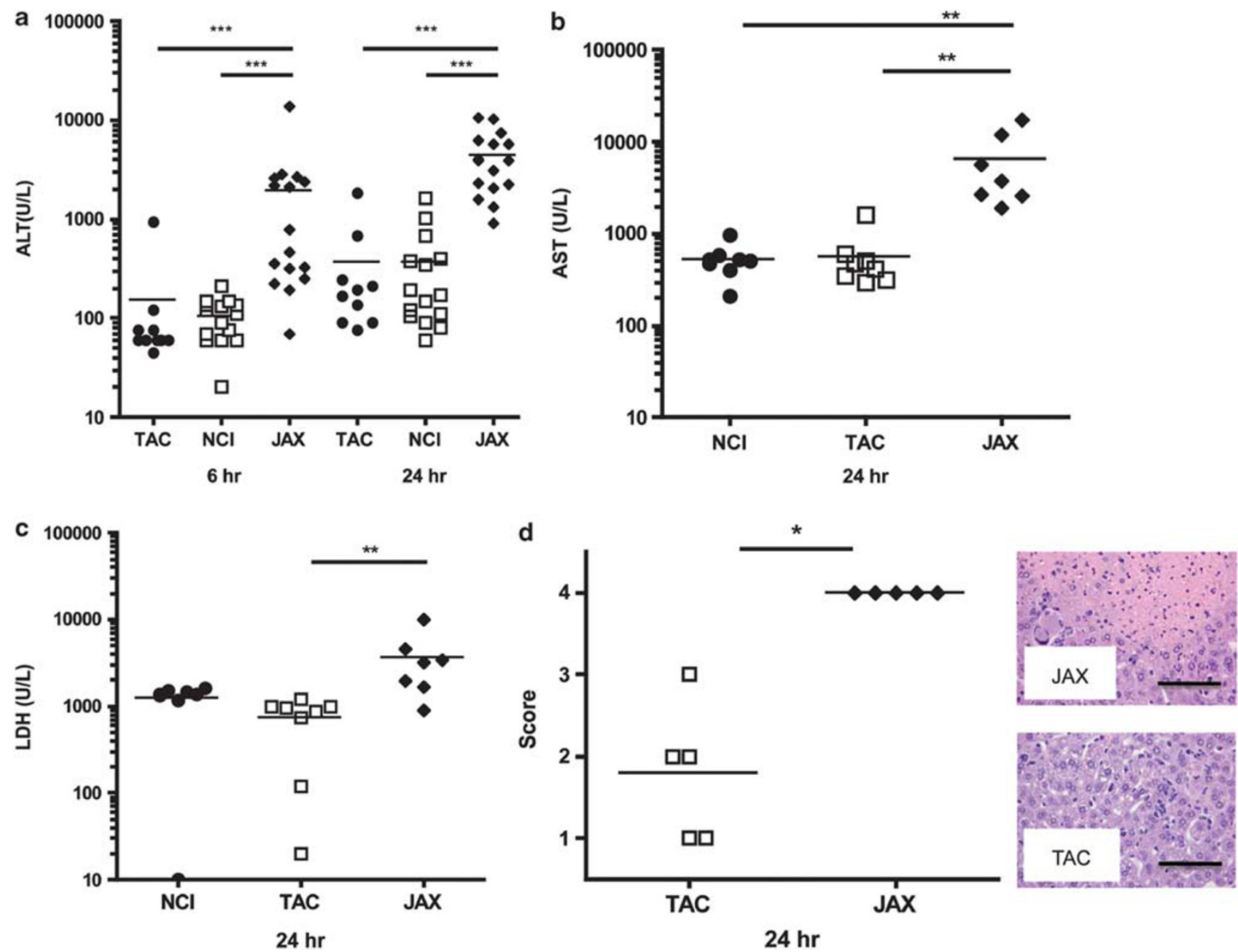

Figure $1 \mathrm{BALB} / \mathrm{c}$ mice from different vendors are differentially susceptible to ConA-induced liver injury. Female 6- to 8-week-old BALB/C mice obtained from vendors as indicated were challenged with ConA (15 $\mu \mathrm{g} / \mathrm{g})$. (a) ALT, (b) AST, and (c) LDH were measured at the indicated time points. Each point represents a single mouse. Short horizontal lines indicate means. The y axis is in log scale. Data are aggregated from three independent experiments. ${ }^{*} P<0.05,{ }^{* *} P<0.01,{ }^{* * *} P<0.001$. (d) Representative H\&E of liver sections (scale bar $=100 \mu \mathrm{m}$ ) and respective histopathological scoring are shown from $\mathrm{BALB} / \mathrm{C} \mathrm{JAX}$ mice and BALB/c TAC mice $24 \mathrm{~h}$ post ConA.

fecal microbiota composition using $16 \mathrm{~S}$ rRNA gene sequencing. Overall, JAX mice and TAC mice had similar diversity in fecal bacteria (Figure 3a). Principal coordinates analysis confirmed that the microbial community structures were strongly influenced by vendor (Figure 3b). Among 441 operational taxonomic units (OTU) identified at the family/ genus level, some OTU were identifiably different in frequency between JAX samples and TAC samples (Figure 3c).

We sought to identify bacterial taxa that may be associated with liver injury. We first examined segmented filamentous bacteria (SFB), a Clostridia species that has previously been associated with intestinal inflammation in mice and is known to be a component of the intestinal flora in $\mathrm{C} 57 \mathrm{Bl} / 6$ mice from TAC but not from JAX. ${ }^{17}$ By SFB-specific qPCR, ${ }^{18}$ SFB was abundant in BALB/c TAC samples, but at or below detection in BALB/c JAX samples (Figure 4a), similar to results for $\mathrm{C} 57 \mathrm{Bl} / 6$ mice. ${ }^{17}$ Only TAC samples yielded signal high enough for assessment of relationship to liver injury; among these, however, there was no correlation between SFB abundance and ALT levels (Figure 4b). Next, we applied a rigorous filter of the microbiome data to identify taxa of reasonable abundance $(>0.05 \%)$, whose frequency correlated with liver injury as quantified using $\operatorname{ALT}\left(R^{2}>0.35\right.$; two-tailed Pearson correlation: $P<0.05)$. This analysis yielded a single family (Ruminococcaceae; frequency: $3-17 \%$ ). The relative amount of Ruminococcaceae in the fecal microbiota among these samples was significantly and positively correlated with susceptibility to ConA-induced liver injury (Figure 4c). Ruminococcaceae is a family of anaerobic Gram $(+)$ bacteria within the class Clostridia, and is distinct from SFB.

\section{Hepatic Immune Cell Composition and Cytokine Profiles in JAX Mice and in TAC Mice}

We sought to identify possible mechanism(s) through which microbiota may regulate susceptibility to ConA. First, we 

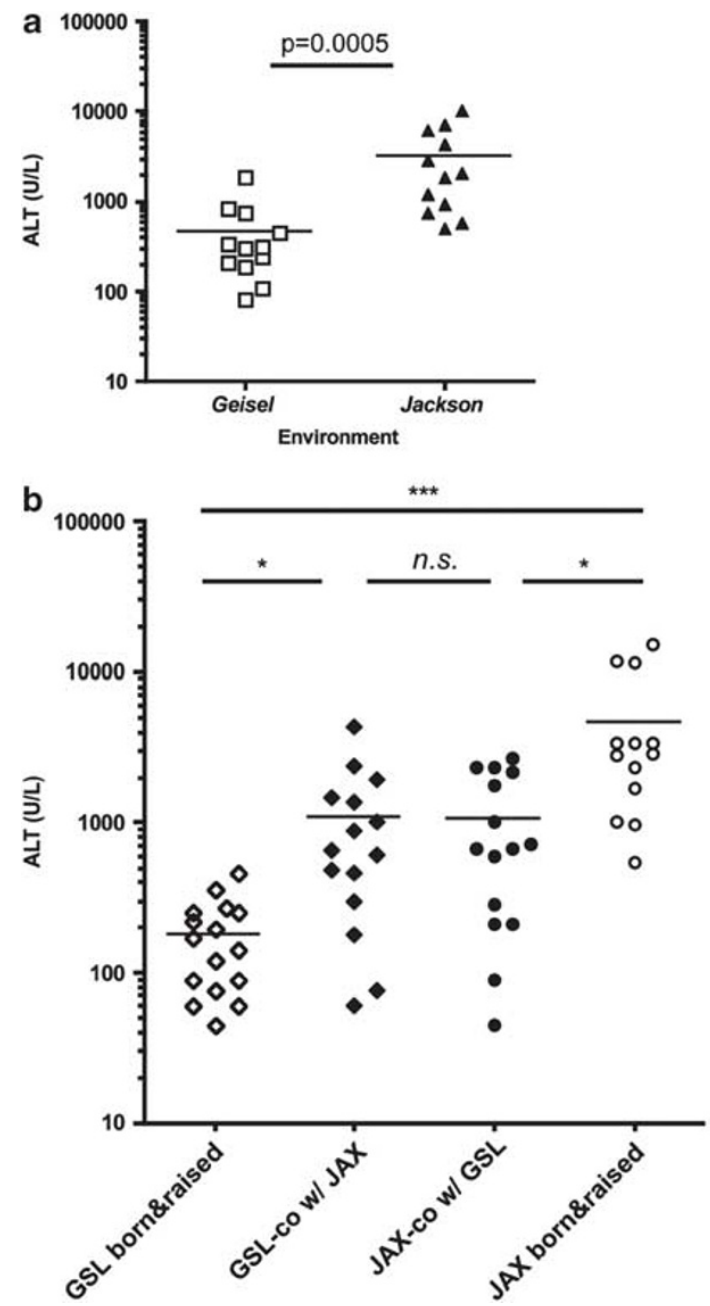

c
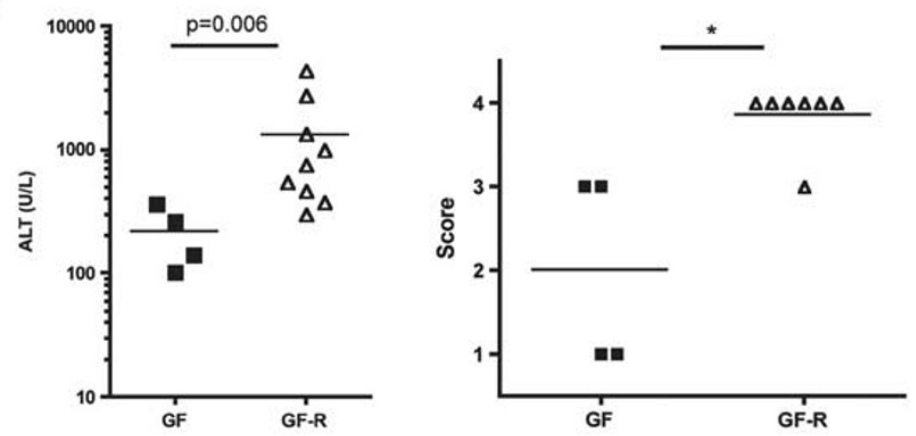

JAX born

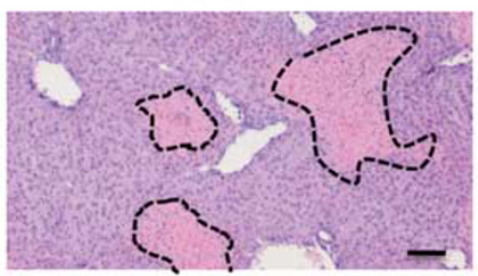

$J A X-C O$
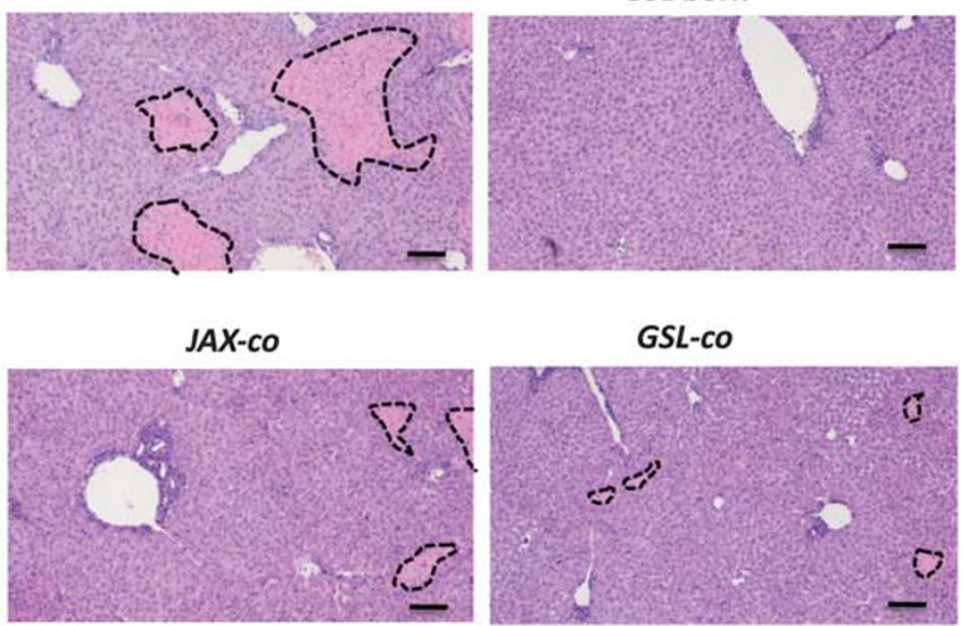

GSL-co

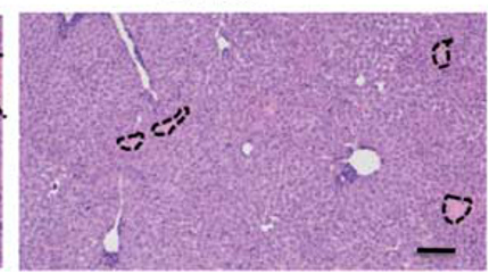

Figure 2 Susceptibility to ConA-induced liver injury is determined by environment, transmissible among co-housed mice, and modulated by commensal bacteria. (a) BALB/cJ mice obtained from JAX were in-bred for several generations at Geisel to allow habituation to the Geisel environment. Age/sex-matched mice were freshly obtained from Jackson Labs. ALT was assessed $24 \mathrm{~h}$ post ConA injection. Data are aggregated from three independent experiments. (b) Three-week-old GSL-habituated female BALB/cJ mice were co-housed with JAX female BALB/cJ mice for 5 weeks (two GSL mice + two JAX mice per cage). Co-housed mice were then ConA challenged, as were age/sex-matched control GSL mice and control JAX mice. Samples were taken at $24 \mathrm{~h}$. Left: ALT data are aggregated from two independent experiments. ${ }^{*} P<0.05$, ${ }^{* * *} P<0.001$. Right: Dotted borders highlight areas of liver cell death. Scale bar $=100 \mu \mathrm{m}$. (c) Five-week-old germ-free (GF) Swiss-Webster (TAC:SW) mice were orally gavaged with fecal contents of age/sex-matched donor JAX BALB/c mice. Five weeks later, conventionalized reconstituted (GF-R) mice (and age/sex-matched non-reconstituted GF mice) were challenged with ConA, and samples taken at $24 \mathrm{~h}$. Plasma ALT levels and histopathological scores (see Materials and Methods) are shown.

considered whether liver resident immune cell number or composition differed significantly between JAX $B A L B / c$ mice and $\mathrm{TAC} \mathrm{BALB} / \mathrm{c}$ mice. Livers from JAX BALB/c mice harbored twice as many $\mathrm{CD} 45^{+}$leukocytes (Figure 5a). Among lymphoid cells, there were no statistically significant differences in frequencies of total T cells, $\mathrm{CD} 4^{+} \mathrm{T}$ cells, iNKT cells, and $\mathrm{B}$ cells. TAC livers harbored a higher frequency of CD8 ${ }^{+}$ $\mathrm{T}$ cells, whereas JAX livers harbored a higher frequency of NK cells (Figure 5b). Among myeloid cells, there were similar frequencies of $\mathrm{CD}_{11 \mathrm{~b}}{ }^{+} \mathrm{Gr} 1^{+}$cell and $\mathrm{CD} 1 \mathrm{~b}^{-} \mathrm{Gr} 1^{+}$cell sub-populations, with JAX livers exhibiting slightly higher frequencies of $\mathrm{CD}_{11 b^{+}} \mathrm{Gr}^{-}$cells, and of $\mathrm{CD} 11 \mathrm{c}^{+}$(dendritic) cells (Figure 5c). As the frequencies of lymphoid cells and myeloid cells were overall similar between JAX and TAC, the higher numbers of $\mathrm{CD} 45^{+}$cells in JAX livers reflect a largely non-specific increase in all $\mathrm{CD} 45^{+}$cells. Since differences in environment result in differences in liver injury that range from 5- to 20-fold (Figures 1 and 2), a difference in liver immune cell numbers of two-fold, with overall similarity in cell composition, seems unlikely to significantly account for differences in ConA susceptibility, and we therefore looked at additional factors.

ConA-induced liver damage is heavily dependent on specific cytokines and chemokines; we therefore examined cytokine production profiles. We prepared lysates of mouse livers $0-24 \mathrm{~h}$ following ConA, and measured numerous cytokines and chemokines by cytokine bead array. Shortly 

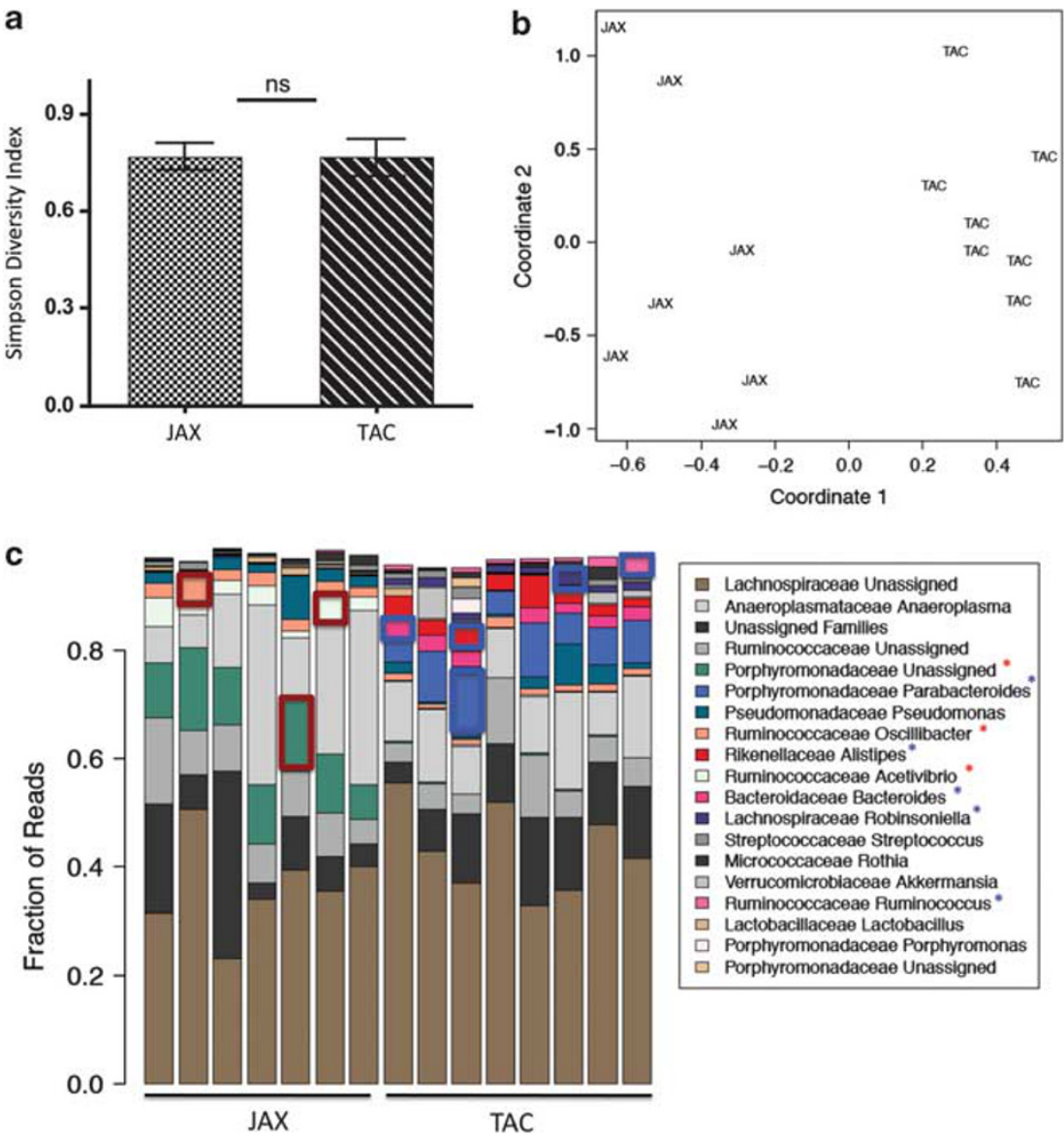

Figure 3 The composition of the fecal microbiota differs by vendor. (a) A Simpson Diversity Index was calculated for 165 ribotyping results from fecal DNA samples from JAX $(n=7)$ and TAC $(n=8)$ BALB/c mice. Bars represent mean \pm s.d. (b) The principal coordinates analysis from $16 \mathrm{~S}$ ribotyping results is shown. TAC samples and JAX samples cluster in distinct groups, indicating that vendor origin determines microbial composition. (c) The taxonomic distributions of fecal microbiomes from JAX mice and TAC mice are presented as the relative abundance of genera (fraction/reads) present in the bacterial communities. In all, 441 total taxa at the genus level were identified, of which the 19 most abundant are annotated to the right. Of these, 8 genera exhibit statistically significant differences in abundance for JAX vs TAC $(P<0.05)$. For each genus, one example is bordered by a thick box (left), and identified by an asterisk (right). Maroon boxes and blue boxes indicate genera that are significantly more abundant in JAX samples and TAC samples, respectively.

after ConA administration, activated iNKT cells release large amounts of interferon (IFN)- $\gamma$, interleukin (IL)-4, and IL-17A respectively, each of which is required for ConA-induced liver damage. ${ }^{21-23}$ Here, IFN- $\gamma$ and IL-4 were rapidly produced in both groups, but were not different between JAX samples and TAC samples, whereas IL-17 was actually higher in TAC samples (Figure 5d). Thus, these data argue against differential Th1/2/17 cytokine release as a relevant mechanism to explain differential injury. For some other cytokines, there were statistically significant but modest differences between JAX samples and TAC samples (Supplementary Figure 4A and B), but most showed no difference (Supplementary Figure 4C), Again, since environment induces dramatic differences in liver injury, the cytokine/chemokine profiles observed do not satisfactorily explain the effect of environment.

\section{Fas Triggering Results in Greater Liver Injury in JAX Mice than in TAC Mice}

We next considered the hypothesis that JAX mice and TAC mice differ in response to triggering of the Fas pathway. Hepatocytes constitutively express the Fas death receptor, and its crosslinking results in acute liver injury. Several reports show that ConA liver injury is dependent on an intact Fas/FasL system, ${ }^{14,24}$ and we independently verified these observations (Supplementary Figure 5). Importantly, Fasdeficient mice and Fas-intact mice raised as littermates, and therefore exposed to similar microbiota, showed significant differences in response to ConA (Figure 6a).

For subsequent experiments, we induced liver injury using a reagent that would directly trigger the Fas response pathway. Jo-2 is an agonistic Fas mAb that rapidly crosslinks Fas and causes acute hepatocyte apoptosis. We injected Jo-2 at 

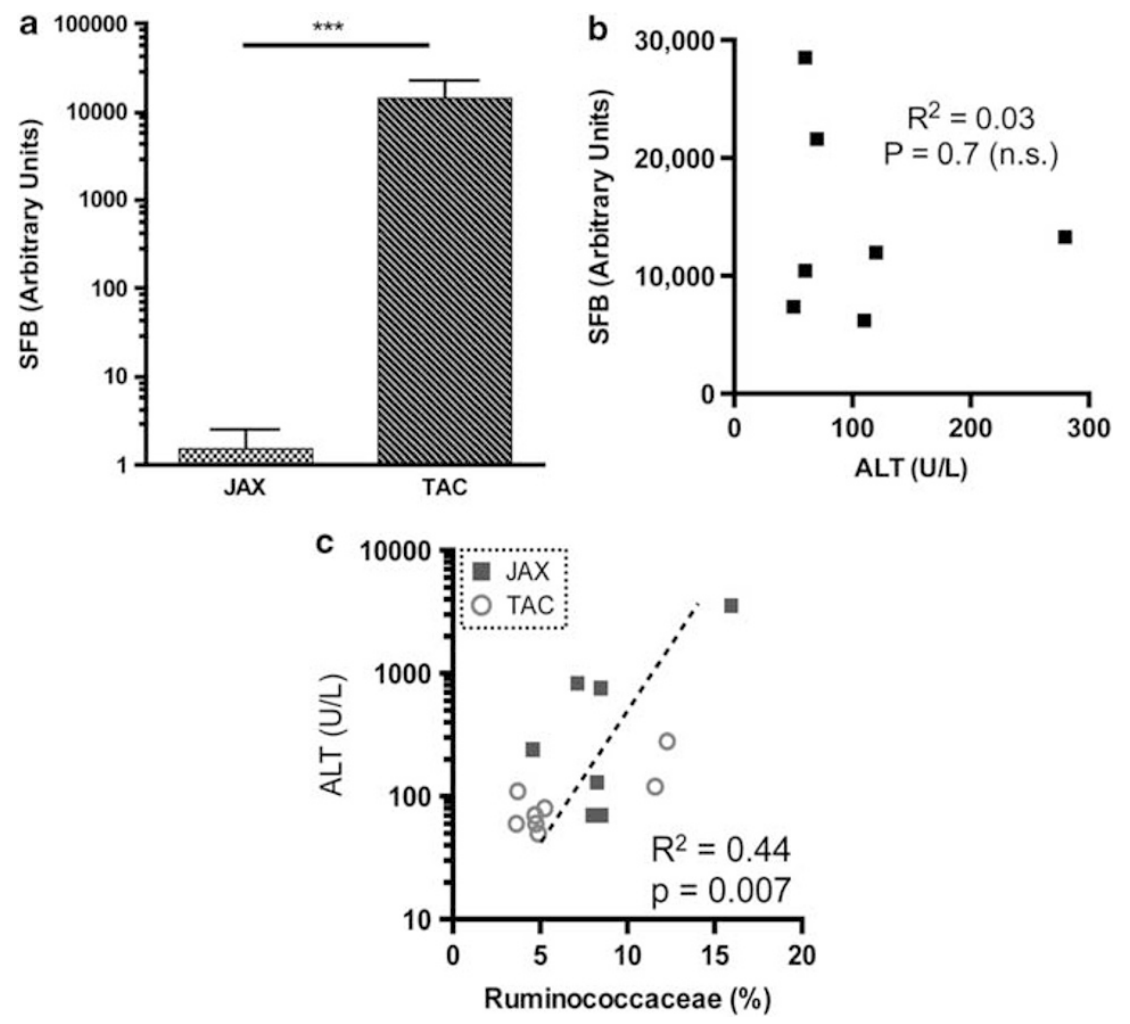

Figure 4 Frequency of bacterial OTUs and their associations with disease phenotype. (a) SFB was measured by taxa-specific 16S QRT-PCR in fecal DNA samples from BALB/c mice. SFB was undetectable in many JAX samples. Bars indicate s.d. ${ }^{* * *} P<0.0001$. (b) For TAC samples, there is no correlation between SFB relative abundance and liver damage. A similar correlation could not be attempted for JAX samples, as SFB was undetectable in many samples. (c) Ruminococcaceae frequency positively correlates with liver injury (ALT measured at $6 \mathrm{~h}$ ). $R^{2}$ and $P$-value (Pearson) are shown.

varying doses to $\mathrm{JAX} \mathrm{BALB} / \mathrm{c}$ mice and to $\mathrm{TAC} \mathrm{BALB} / \mathrm{c}$ mice, and measured ALT at 10 and $24 \mathrm{~h}$. Liver damage was much more severe in JAX mice than in TAC mice, particularly at higher doses (Figure $6 \mathrm{~b}$ and $\mathrm{c}$ ), a finding confirmed in multiple repeat experiments using a single dose of Jo-2 (Supplementary Figure 6). In additional studies, we observed no difference in liver damage between JAX mice and TAC mice following acute challenge with $\mathrm{CCl}_{4}$ (Supplementary Figure 7), a hepatotoxic agent that injures liver through oxidative stress. Thus, a difference in susceptibility to liver injury is observed between JAX mice and TAC mice in response to some types of injury (ConA and Fas), but not others $\left(\mathrm{CCl}_{4}\right)$.

\section{Microbiota Regulates Sensitivity to Fas-Induced Liver Injury: Requirement for MyD88 Signaling}

To test whether the sensitivity of mice to liver damage induced by Fas triggering is modulated by microbiota, we treated JAX mice with oral antibiotics for 2 weeks. Quantitative 16S PCR of fecal contents confirmed effective reduction in fecal bacteria load by $\sim 500$-fold (Figure 7a); in addition, enlargement of the cecum was observed, as commonly found after severe reduction in commensal organisms (Figure $7 \mathrm{~b}$; compare top vs bottom). Furthermore, treatment with antibiotics did not impact liver baseline ALT levels (Supplementary Figure 8A). Treatment with antibiotics greatly reduced Fas-induced liver damage (Figure 7c; Supplementary Figure 8B). Conversely, GF Swiss-Webster mice that had been reconstituted with JAX commensal bacteria were significantly more sensitive to Fasinduced liver damage than were non-reconstituted GF mice (Figure 7d; Supplementary Figure 8C). Finally, mice deficient in the TLR adaptor molecule MyD88 mice were more resistant to Fas-induced liver damage than were littermate MyD88intact mice (Figure 7e; Supplementary Figure 8D).

\section{DISCUSSION}

The intestinal microbiota profoundly affects immune system development ${ }^{25,26}$ and influences intestinal and extra-intestinal inflammatory disease. ${ }^{27,28}$ The intestinal microbiota influences the progression of chronic liver diseases such as non-alcoholic steatohepatitis, ${ }^{29}$ chronic viral hepatitis, ${ }^{30}$ and alcoholic liver disease ${ }^{31}$ Our data show that the microbiota can also modulate acute liver injury. Moreover, to our knowledge this is the first report showing that the microbiota can regulate the extent of liver injury caused by activation of the Fas pathway. It is important to point out that our studies examined primarily $\mathrm{BALB} / \mathrm{c}$ mice, and to some extent $\mathrm{C} 57 \mathrm{Bl} /$ 6 mice, two of the most commonly used inbred experimental 

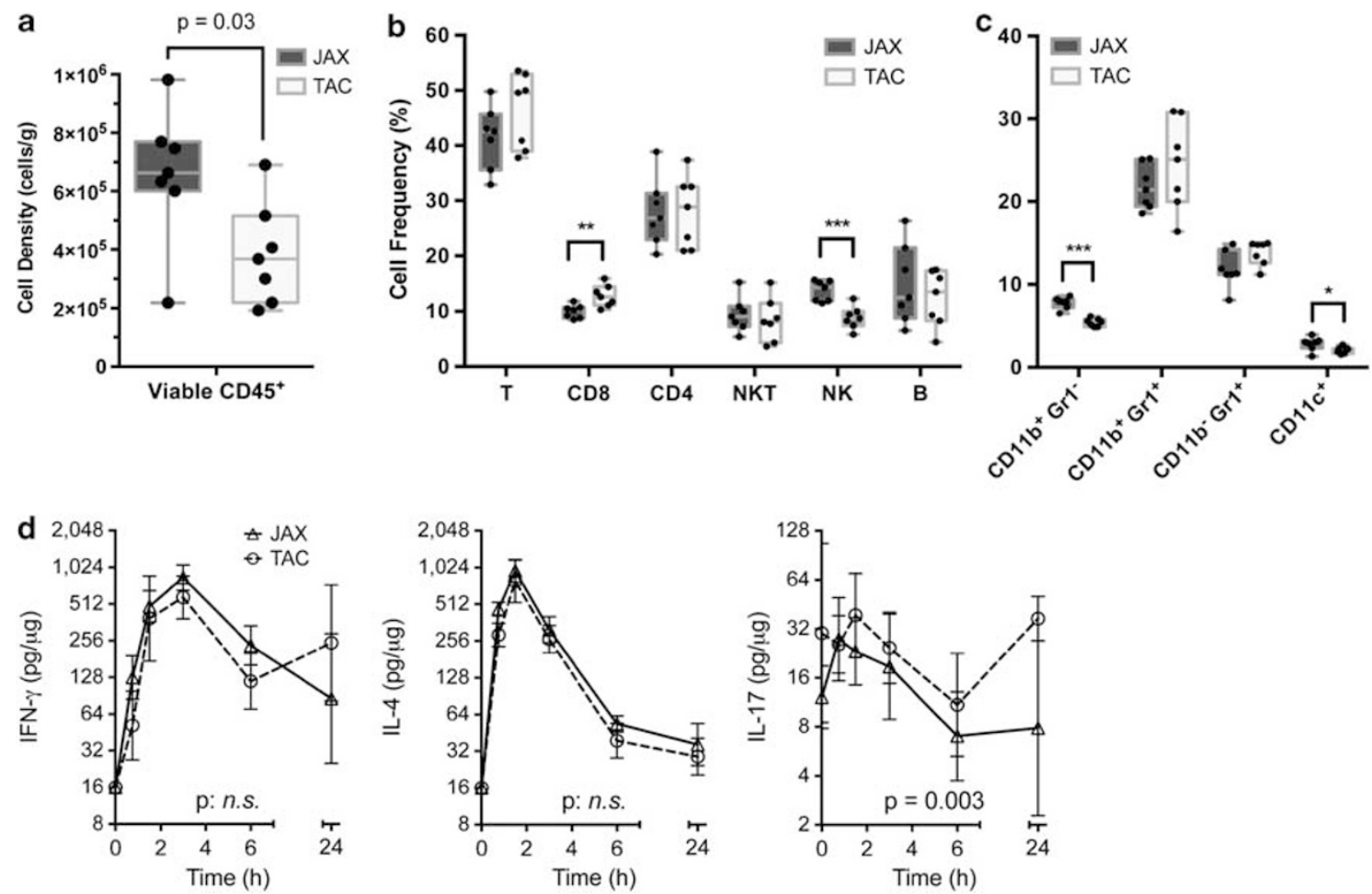

Figure 5 Resident liver immune cells and ConA-induced cytokine profiles are similar between JAX livers and TAC livers. (a) Liver MNC were isolated from naïve JAX BALB/C mice and naïve TAC BALB/C mice and total CD45 + cells quantified by FACS. Each symbol represents a single mouse, and results are aggregated in box-and-whiskers plots. (b, c) Frequencies of liver (b) lymphoid (T (TCR $\beta+), C D 4+T, C D 8+T, N K T(C D 1 d+T C R \beta+)$, NK $(\mathrm{CD} 49 \mathrm{~b}+\mathrm{TCR} \beta-), \mathrm{B}(\mathrm{CD} 19+))$ and (c) myeloid (monocytic/macrophage (CD11b + Gr1 + and CD11b + Gr1 - ), neutrophils (CD11b-Gr1 +), dendritic cells $(C D 11 \mathrm{c}+))$ cells in naïve JAX mice and TAC mice were obtained. Data are representative of three independent experiments. ${ }^{*} P<0.05, * * P<0.01$, ${ }^{* * *} P<0.001$. (d) Cytokine profiles of liver lysates from BALB/c mice collected before $(0 \mathrm{~h})$ and after $(0.75 \mathrm{~h}, 1.5 \mathrm{~h}, 3 \mathrm{~h}, 6 \mathrm{~h}, 24 \mathrm{~h})$ ConA injection. Cytokines were quantified by cytokine bead array. $N=6$ mice per vendor and time point. $P$-values (ANOVA) are shown for each cytokine. y axes are log ${ }_{2}$ scale.

mouse strains; additional work is needed to determine whether our findings would extend to other mouse strains, or to other species, including humans.

Triggering of Fas-mediated cell death in BALB/c mice through ConA activation of $\mathrm{T}$ cells and other immune cells, or by direct activation of the Fas pathway, leads to different degrees of liver injury depending on the status of the microbiota. GF mice exhibit low levels of liver damage following administration of either ConA or anti-Fas, and conventionalization with JAX microbiota restores sensitivity to either agent. In addition, antibiotic treatment results in a reduction in intestinal bacterial load, and in liver injury following direct Fas triggering. Together, these findings show that the liver is under active regulation by the microbiota, which acts as a rheostat, regulating the sensitivity of the liver to triggering of cell death by Fas.

Recent work shows that the phenotypes and activities of iNKT cells are established by the microbiota during early postnatal colonization of the intestine. ${ }^{32,33}$ Indeed, early in the course of these studies, we expected that, since liver damage in response to ConA is strongly dependent upon iNKT cells, ${ }^{22,34}$ the influence of the microbiota on acute $\mathrm{T}$ cell-mediated liver injury would be mediated at the level of the iNKT cell compartment. However, our data indicate otherwise. First, the frequency of liver iNKT cells is similar in JAX mice and TAC mice. Second, the early increases in IFN- $\gamma$ and IL-4, released by iNKT cells, ${ }^{35}$ are equivalent in JAX livers vs TAC livers. By contrast, the response to Fas triggering is markedly different, with a 5 - to 10 -fold difference in liver injury between mice raised in high-sensitivity environments (JAX) vs low-sensitivity environments (TAC; GSL). Thus, whereas the iNKT phenotype is imprinted by early exposure to microbes, and for which interventions in the adult may be 'too late', the Fas rheostat is much more sensitive to dynamic environmental conditions, specifically the status of the intestinal microbiota.

The TLR adaptor molecule MyD88 is likely an important component of this rheostat, as livers from MyD88 knockout mice exhibited much less damage compared with littermate MyD88 wild-type mice following Fas triggering. Notably, a recent study shows that the structures of the intestinal microbiota in MyD88 knockout, heterozygous, and wild-type mice are indistinguishable among littermates; rather, vertical transmission from the mother is the key determinant of 
a

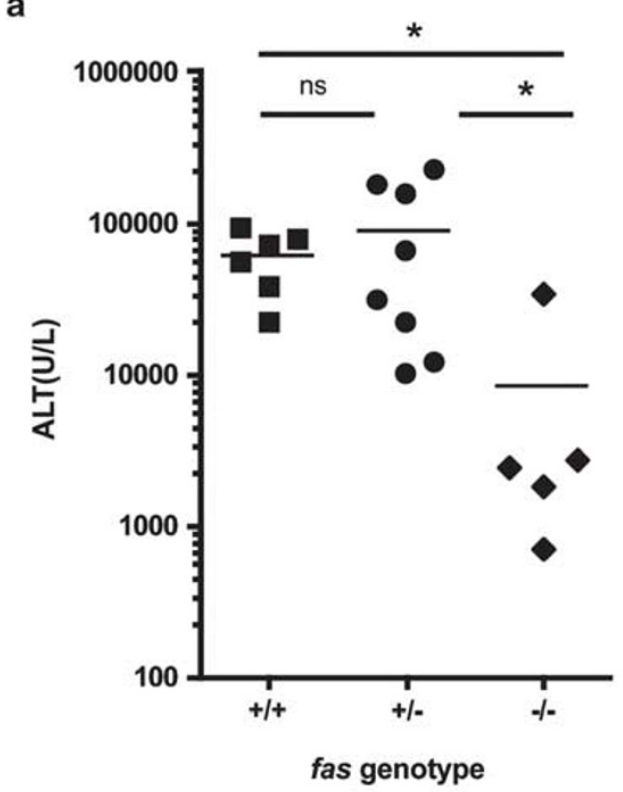

b

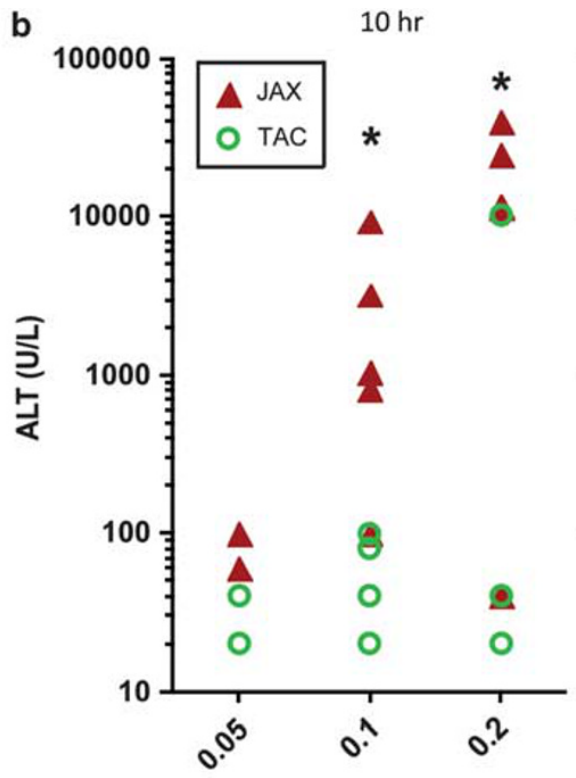

Jo-2 $(\mu \mathrm{g} / \mathrm{g})$

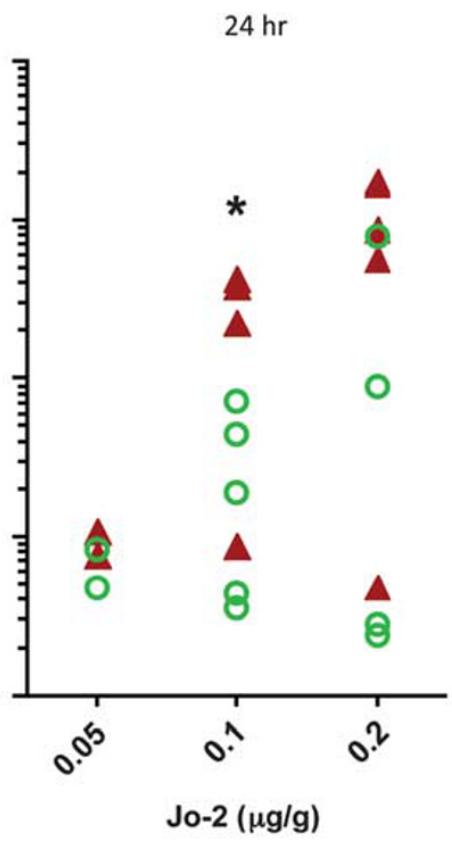

C
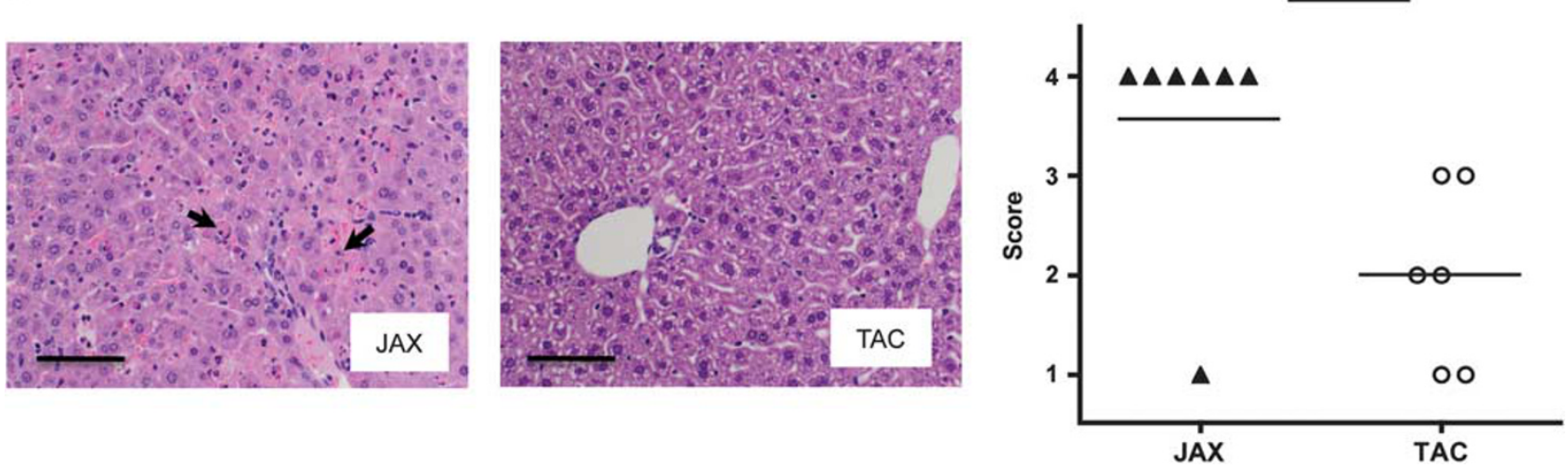

Figure 6 The Fas death receptor is critical for ConA liver injury and direct Fas triggering results in greater liver injury in JAX mice than in TAC mice. (a) Littermate homozygous Fas-deficient $(-/-)$, heterozygous $(+/-)$, and homozygous wild-type $(+/+)$ mice were ConA challenged and liver and blood taken at $24 \mathrm{~h}$. Data are aggregated from results from two litters. (b) BALB/C JAX mice and BALB/C TAC mice were injected with anti-Fas (Jo-2) at the indicated doses. Blood was harvested at $10 \mathrm{~h}$ (left) and $24 \mathrm{~h}$ (right) and ALT measured. (c) Histopathological scoring of TAC livers and JAX livers $6 \mathrm{~h}$ after Jo-2 injection $(0.1 \mu \mathrm{g} / \mathrm{g})$ shows more severe pathology in JAX livers. Arrows indicate pyknotic nuclei, consistent with apoptosis. Scale bar $=100 \mu \mathrm{m}$. ${ }^{*} P<0.05$.

intestinal microbial composition. ${ }^{36}$ This supports a model in which the role of MyD88 here is to participate in providing 'real time' information on the status of the microbiota, rather than to serve as a primary determinant in establishing the structure of the microbiota.

In our hands, $16 \mathrm{~S}$ rRNA sequencing revealed several OTU differences between the microbiota composition of BALB/c JAX and TAC mice. This is consistent with the findings of Ivanov et al ${ }^{25}$ involving C57BL/6 mice from these two vendors. JAX C57Bl/6 mice and TAC C57Bl/6 mice displayed distinct microbiota composition, particularly in the levels of $\mathrm{SFB}$. We found similar results in BALB/c mice, in which SFB was detected only in TAC mice but not in JAX mice. Several studies have correlated disease phenotype with the presence or absence of $\mathrm{SFB}^{37,38}$ In our studies, however, we found no significant correlations between levels of SFB and disease severity (in TAC mice), which suggests that SFB is likely not directly involved in driving the phenotype difference.

Notably, we found that abundance of Ruminococcaceae, another member of Clostridia, was positively correlated with the degree of liver injury in both JAX mice and TAC mice. Interestingly, Ruminococcaceae species have been found to be elevated in ulcerative colitis, ${ }^{39-41}$ which is strongly associated with concomitant liver disease such as primary sclerosing cholangitis. ${ }^{42,43}$ Furthermore, Ruminococcaceae is mucolytic, producing enzymes that facilitate the breakdown of mucin ${ }^{44,45}$ thus potentially affecting intestinal barrier and bacterial translocation. Although Ruminococcaceae is a very 
a

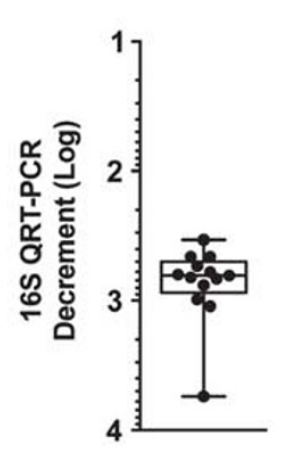

d

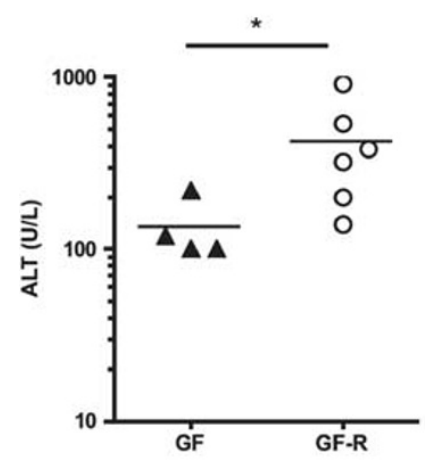

b

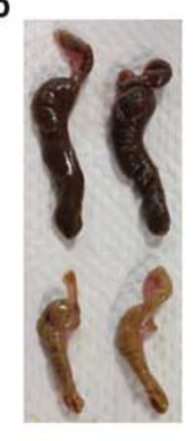

c

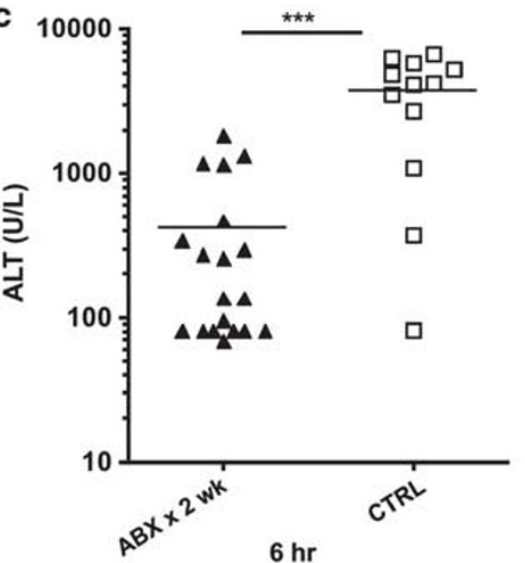

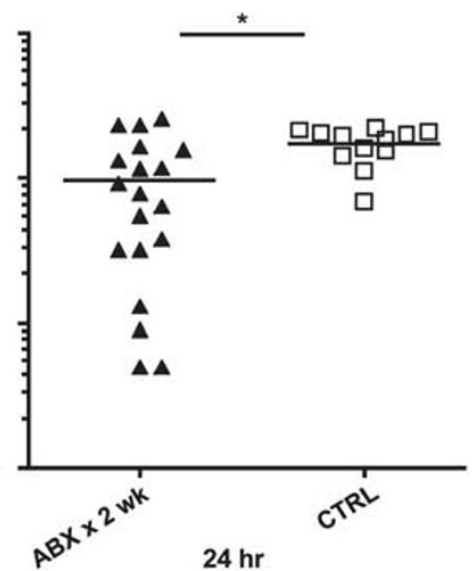

$24 \mathrm{hr}$
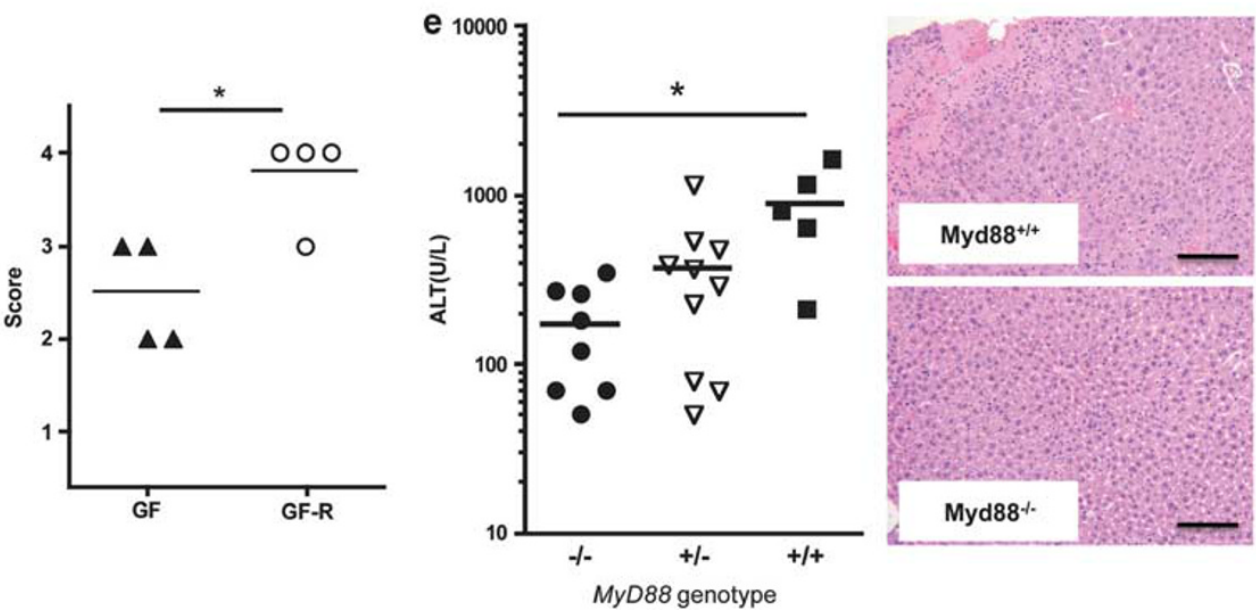

Figure 7 Microbiota regulates sensitivity to Fas-induced liver injury through an MyD88-dependent pathway. (a) Fecal matter was collected from BALB/ cJ mice before and after 2 weeks of antibiotics treatment. DNA was extracted and 16S qRT-PCR was used to assess the fold bacterial load reduction. Each point represents a single mouse. (b) Representative images show that treatment with antibiotics (top two ceca) leads to cecal enlargement compared with control treatment (bottom two ceca). (c) After 2 weeks of antibiotic (ABX) treatment and recovery for 2 days, treated $(n=19)$ and control $(n=12)$ JAX BALB/c mice were injected with Jo-2 $(0.1 \mu \mathrm{g} / \mathrm{g})$. ALT was measured at $6 \mathrm{~h}$ (left) and $24 \mathrm{~h}$ (right) post injection. (d) Five-week-old germ-free (GF) Swiss-Webster (TAC:SW) mice were orally gavaged with fecal contents of age-matched JAX mice. Five weeks later, reconstituted mice (GF-R) and age-matched GF mice were challenged with Jo-2, and killed at $24 \mathrm{~h}$. Plasma ALT levels and histopathological scores are shown. (e) Six- to eight-week-old homozygous Myd88-deficient $(-/-)$, heterozygous $(+/-)$, and homozygous wild-type $(+/+)$ mice that were born and raised as littermates were injected with Jo-2. ALT and representative H\&E (scale bar $=100 \mu \mathrm{m}$ ) are shown at $6 \mathrm{~h}$ post injection. ALT data are aggregated from three litters. ${ }^{*} P<0.05 ;{ }^{* *} P<0.001$.

attractive candidate due to the aforementioned reasons, further investigation is warranted to assess the significance of the positive correlation between the frequency of this bacterial family and acute liver injury following ConA.

Notably, there is precedence for modulation of the Fas response pathway in liver: injection of anti-Fas into mice 1 day after partial hepatectomy results in an increase in hepatocyte proliferation, whereas the same treatment in sham-operated mice causes acute apoptosis. This modification of response to anti-Fas is associated with an increase in expression of c-FLIP, a critical regulator that inhibits Fasmediated apoptosis. ${ }^{46}$ However, the microbiota may exert effects on cells other than hepatocytes. Liver damage following Fas triggering appears to involve the participation of non-parenchymal cells, such as Kupffer cells, that serve to amplify liver injury, perhaps in response to release of cytokines and other danger signals from dying hepatocytes. ${ }^{10,47}$

One implication of our findings that the microbiota modulates responses to direct Fas triggering is that an alteration (intentional or otherwise) in the composition of gut bacteria may concomitantly alter the course of inflammatory liver diseases in which Fas has a critical role. Since Fas is implicated in most forms of liver injury, ${ }^{48}$ these findings may have prognostic and therapeutic importance not only for acute hepatitis but also for the progression to chronicity, cirrhosis, and hepatocellular carcinoma. Experimental inhibition of Fas expression in liver using siRNA is effective at reducing injury after ConA; ${ }^{49}$ similarly, inhibition of Caspase8 expression by siRNA inhibits liver injury induced by direct Fas triggering. ${ }^{50}$ The possibility of modulating the 
microbiota to regulate Fas sensitivity may be an attractive therapeutic option for inflammatory disease of the liver.

Supplementary Information accompanies the paper on the Laboratory Investigation website (http://www.laboratoryinvestigation.org)

\section{ACKNOWLEDGMENTS}

We thank Beverly Gorham and Christine Kretowicz for mouse breeding and genotyping, and the Clinical Laboratory at Dartmouth-Hitchcock Medical Center for ALT, AST and LDH measurements. We thank the shared resources at the Norris Cotton Cancer Center, including the DartMouse Speed Congenics core laboratory for genetic background analysis, and DartLab for running cytokine bead array assay and for technical assistance. We are grateful to Sharon Grim and Joseph Vineis for amplicon library construction and sequencing. This work was supported by National Institutes of Health grants R01Al078195 (JDG), R37Al83256 (GAO), P30GM103415 grant from the Center of Biomedical Research Excellence in Molecular, Cellular, and Translation Immunological Research (JDG) and the Cystic Fibrosis Foundation Research Development 399 Program (STANTO07R0). JD was supported by National Institutes of Health training grant T32AI007363.

\section{DISCLOSURE/CONFLICT OF INTEREST}

The authors declare no conflict of interest.

1. Qin J, Li R, Raes J, Arumugam M, Burgdorf KS, Manichanh C, et al. A human gut microbial gene catalogue established by metagenomic sequencing. Nature 2010;464:59-65.

2. Chassaing B, Etienne-Mesmin L, Gewirtz AT. Microbiota-liver axis in hepatic disease. Hepatology 2014;59:328-339.

3. Henao-Mejia J, Elinav E, Thaiss CA, Licona-Limon P, Flavell RA. Role of the intestinal microbiome in liver disease. J Autoimmun 2013;46:66-73.

4. Carvalho FA, Aitken JD, Vijay-Kumar M, Gewirtz AT. Toll-like receptorgut microbiota interactions: perturb at your own risk! Annu Rev Physiol 2012;74:177-198.

5. Szabo G, Bala S, Petrasek J, Gattu A. Gut-liver axis and sensing microbes. Dig Dis 2010;28:737-744.

6. Ojiro K, Ebinuma $\mathrm{H}$, Nakamoto $\mathrm{N}$, Wakabayashi $\mathrm{K}$, Mikami $\mathrm{Y}$, Ono $\mathrm{Y}$, et al. MyD88-dependent pathway accelerates the liver damage of Concanavalin A-induced hepatitis. Biochem Biophys Res Commun 2010:399:744-749.

7. Lin $\mathrm{Y}, \mathrm{Yu} \mathrm{L}-\mathrm{X}$, Yan $\mathrm{H}-\mathrm{X}$, Yang $\mathrm{W}$, Tang L, Zhang H-L, et al. Gut-derived lipopolysaccharide promotes T-cell-mediated hepatitis in mice through Toll-like receptor 4. Cancer Prev Res (Phila) 2012;5:1090-1102.

8. Tsung A, Hoffman RA, Izuishi K, Critchlow ND, Nakao A, Chan MH, et al. Hepatic ischemia/reperfusion injury involves functional TLR4 signaling in nonparenchymal cells. J Immunol 2005;175:7661-7668.

9. Jiang W, Sun R, Zhou R, Wei H, Tian Z. TLR-9 activation aggravates concanavalin A-induced hepatitis via promoting accumulation and activation of liver CD4 + NKT cells. J Immunol 2009;182:3768-3774.

10. Imaeda AB, Watanabe A, Sohail MA, Mahmood S, Mohamadnejad M, Sutterwala FS, et al. Acetaminophen-induced hepatotoxicity in mice is dependent on TIr9 and the Nalp3 inflammasome. J Clin Invest 2009;119:305-314.

11. Tiegs G, Hentschel J, Wendel A. A T cell-dependent experimental liver injury in mice inducible by concanavalin A. J Clin Invest 1992;90: 196-203.

12. Nakamoto $\mathrm{N}$, Ebinuma $\mathrm{H}$, Kanai $\mathrm{T}$, Chu P-S, Ono $\mathrm{Y}$, Mikami $\mathrm{Y}$, et al. CCR9 + macrophages are required for acute liver inflammation in mouse models of hepatitis. Gastroenterology 2012;142:366-376.

13. Hatada $S$, Ohta $T$, Shiratsuchi $Y$, Hatano M, Kobayashi $Y$. A novel accessory role of neutrophils in concanavalin A-induced hepatitis. Cell Immunol 2005:233:23-29.

14. Tagawa Y, Kakuta S, Iwakura Y. Involvement of Fas/Fas ligand systemmediated apoptosis in the development of concanavalin A-induced hepatitis. Eur J Immunol 1998;28:4105-4113.

15. Cripps JG, Wang J, Maria A, Blumenthal I, Gorham JD. Type $1 \mathrm{~T}$ helper cells induce the accumulation of myeloid-derived suppressor cells in the inflamed Tgfb1 knockout mouse liver. Hepatology 2010;52: $1350-1359$.
16. Upadhyay V, Poroyko V, Kim T-J, Devkota S, Fu S, Liu D, et al. Lymphotoxin regulates commensal responses to enable diet-induced obesity. Nat Immunol 2012;13:947-953.

17. Ivanov II, Atarashi K, Manel N, Brodie EL, Shima T, Karaoz U, et al. Induction of intestinal Th17 cells by segmented filamentous bacteria. Cell 2009;139:485-498.

18. Barman M, Unold D, Shifley K, Amir E, Hung K, Bos N, et al. Enteric salmonellosis disrupts the microbial ecology of the murine gastrointestinal tract. Infect Immun 2008;76:907-915.

19. Eren A. M, Vineis J. H, Morrison H. G, Sogin M. L. A filtering method to generate high quality short reads using Illumina Paired-End Technology. PLoS ONE 2013;8:e66643.

20. Price KE, Hampton TH, Gifford AH, Dolben EL, Hogan DA, Morrison HG, et al. Unique microbial communities persist in individual cystic fibrosis patients throughout a clinical exacerbation. Microbiome 2013;1:27.

21. Küsters $S$, Gantner F, Künstle G, Tiegs G. Interferon gamma plays a critical role in $T$ cell-dependent liver injury in mice initiated by concanavalin A. Gastroenterology 1996;111:462-471.

22. Toyabe S, Seki S, liai T, Takeda K, Shirai K, Watanabe $\mathrm{H}$, et al. Requirement of IL-4 and liver NK1 + T cells for concanavalin A-induced hepatic injury in mice. J Immunol 1997;159:1537-1542.

23. Yan S, Wang L, Liu N, Wang Y, Chu Y. Critical role of interleukin-17/ interleukin-17 receptor axis in mediating Con A-induced hepatitis. Immunol Cell Biol 2012;90:421-428.

24. Seino K, Kayagaki N, Takeda K, Fukao K, Okumura K, Yagita H. Contribution of Fas ligand to $\mathrm{T}$ cell-mediated hepatic injury in mice. Gastroenterology 1997;113:1315-1322.

25. Ivanov II, Frutos R de L, Manel N, Yoshinaga K, Rifkin DB, Sartor RB, et al. Specific microbiota direct the differentiation of IL-17-producing T-helper cells in the mucosa of the small intestine. Cell Host Microbe 2008;4:337-349.

26. Atarashi K, Tanoue T, Shima T, Imaoka A, Kuwahara T, Momose Y, et al. Induction of colonic regulatory $\mathrm{T}$ cells by indigenous Clostridium species. Science 2011;331:337-341.

27. Fuhrer A, Sprenger N, Kurakevich E, Borsig L, Chassard C, Hennet T. Milk sialyllactose influences colitis in mice through selective intestinal bacterial colonization. J Exp Med 2010;207:2843-2854.

28. Berer $K$, Mues $M$, Koutrolos $M$, Rasbi ZA, Boziki $M$, Johner $C$, et al. Commensal microbiota and myelin autoantigen cooperate to trigger autoimmune demyelination. Nature 2011;479:538-541.

29. Mouzaki M, Comelli EM, Arendt BM, Bonengel J, Fung SK, Fischer SE, et al. Intestinal microbiota in patients with nonalcoholic fatty liver disease. Hepatology 2013;58:120-127.

30. Sandler NG, Koh C, Roque A, Eccleston JL, Siegel RB, Demino M, et al. Host response to translocated microbial products predicts outcomes of patients with HBV or HCV infection. Gastroenterology 2011;141: 1220-1230, 1230.e1-3.

31. French SW. Mechanisms of alcoholic liver injury. Can J Gastroenterol 2000;14:327-332.

32. Olszak T, An D, Zeissig S, Vera MP, Richter J, Franke A, et al. Microbial exposure during early life has persistent effects on natural killer $\mathrm{T}$ cell function. Science 2012;336:489-493.

33. Wei B, Wingender G, Fujiwara D, Chen DY, McPherson M, Brewer S, et al. Commensal microbiota and CD8 + T cells shape the formation of invariant NKT cells. J Immunol 2010;184:1218-1226.

34. Takeda K, Hayakawa Y, Van Kaer L, Matsuda H, Yagita H, Okumura K. Critical contribution of liver natural killer T cells to a murine model of hepatitis. Proc Natl Acad Sci USA 2000;97:5498-5503.

35. Kaneko Y, Harada M, Kawano T, Yamashita M, Shibata Y, Gejyo F, et al. Augmentation of Valpha14 NKT cell-mediated cytotoxicity by interleukin 4 in an autocrine mechanism resulting in the development of concanavalin A-induced hepatitis. J Exp Med 2000;191:105-114.

36. Ubeda C, Lipuma L, Gobourne A, Viale A, Leiner I, Equinda M, et al. Familial transmission rather than defective innate immunity shapes the distinct intestinal microbiota of TLR-deficient mice. J Exp Med 2012;209:1445-1456.

37. Wu H-J, Ivanov II, Darce J, Hattori K, Shima T, Umesaki Y, et al. Gutresiding segmented filamentous bacteria drive autoimmune arthritis via T helper 17 cells. Immunity 2010;32:815-827.

38. Kriegel MA, Sefik E, Hill JA, Wu H-J, Benoist C, Mathis D. Naturally transmitted segmented filamentous bacteria segregate with diabetes protection in nonobese diabetic mice. Proc Natl Acad Sci USA 2011;108(28):11548-11553. 
39. Png CW, Lindén SK, Gilshenan KS, Zoetendal EG, McSweeney CS, Sly LI, et al. Mucolytic bacteria with increased prevalence in IBD mucosa augment in vitro utilization of mucin by other bacteria. Am Gastroenterol 2010;105:2420-2428.

40. Joossens $M$, Huys $G$, Cnockaert $M$, De Preter $V$, Verbeke $K$ Rutgeerts $\mathrm{P}$, et al. Dysbiosis of the faecal microbiota in patients with Crohn's disease and their unaffected relatives. Gut 2011;60: 631-637.

41. Willing BP, Dicksved J, Halfvarson J, Andersson AF, Lucio M, Zheng Z, et al. A pyrosequencing study in twins shows that gastrointestina microbial profiles vary with inflammatory bowel disease phenotypes. Gastroenterology 2010;139:1844-1854.e1.

42. O'Toole A, Alakkari A, Keegan D, Doherty G, Mulcahy H, O'Donoghue D Primary sclerosing cholangitis and disease distribution in inflammatory bowel disease. Clin Gastroenterol Hepatol 2012;10:439-441.

43. Loftus EV, Harewood GC, Loftus CG, Tremaine WJ, Harmsen WS Zinsmeister AR, et al. PSC-IBD: a unique form of inflammatory bowel disease associated with primary sclerosing cholangitis. Gut 2005;54:91-96.

44. Hoskins LC, Boulding ET. Degradation of blood group antigens in human colon ecosystems. I. In vitro production of $\mathrm{ABH}$ blood group- degrading enzymes by enteric bacteria. J Clin Invest 1976;57: 63-73.

45. Hoskins LC, Boulding ET. Mucin degradation in human colon ecosystems. Evidence for the existence and role of bacterial subpopulations producing glycosidases as extracellular enzymes. J Clin Invest 1981;67:163-172.

46. Desbarats J, Newell MK. Fas engagement accelerates liver regeneration after partial hepatectomy. Nat Med 2000;6:920-923.

47. Matsuki Y, Li L, Hsu H-C, Yang PA, Zheng R, Edwards CK, et al. Soluble Fas gene therapy protects against Fas-mediated apoptosis of hepatocytes but not the lethal effects of Fas-induced TNF-alpha production by Kupffer cells. Cell Death Differ 2002;9:626-635.

48. Liedtke C, Trautwein C. The role of TNF and Fas dependent signaling in animal models of inflammatory liver injury and liver cancer. Eur J Cell Biol 2012;91:582-589.

49. Song $E_{\text {, Lee }} \mathrm{S}-\mathrm{K}$, Wang J, Ince $\mathrm{N}$, Ouyang $\mathrm{N}$, Min J, et al. RNA interference targeting Fas protects mice from fulminant hepatitis. Nat Med 2003;9:347-351.

50. Zender L, Hutker S, Liedtke C, Tillmann HL, Zender S, Mundt B, et al. Caspase 8 small interfering RNA prevents acute liver failure in mice. Proc Natl Acad Sci USA 2003;100:7797-7802. 